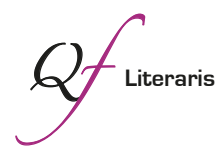

\title{
Cantar espanto. Escrituras poéticas en el universo concentracionario chileno
}

\author{
Jaume Peris Blanes \\ Universitat de València \\ Jaume.peris@uv.es
}

\begin{abstract}
Resumen: El artículo analiza la escritura poética producida en el interior de los campos de concentración chilenos, en su mayoría por autores anónimos. Se analizan las condiciones extremas de esas escrituras y algunos de sus rasgos fundamentales, partiendo de la idea de que el sistema concentracionario no sólo hace trizas el mundo de los detenidos, sino también su lenguaje. Tras abordar los poemas anónimos, el artículo se detiene en el análisis de algunos poemas de Aristóteles España y en el poema inacabado de Víctor Jara escrito en el interior del Estadio Chile, pocas horas antes de morir. En ellos puede localizarse una conceptualización incisiva del lugar de la poesía concentracionaria chilena.
\end{abstract}

Palabras clave: poesía concentracionaria; Chile; campos de concentración; Aristóteles España; Víctor Jara.

\section{"Cantar espanto". Poetic writing in the Chilean concentrationary universe}

Abstract: The article focuses the poetry produced within Chilean concentration camps, mostly by anonymous authors. The author deals with the extreme conditions of those scriptures and some of its fundamental features, based on the idea that the concentration camp system not only shatters the world of detainees but also their language. After analyzing the anonymous poems the author focuses on some poems of Aristóteles España and the unfinished poem by Víctor Jara, written inside the Chile Stadium, a few hours before his murder. Keywords: concentrationary poetry; Chile; concentration camps; Aristóteles España; Víctor Jara. 

Las islas de Chile son campos de concentración

Chile es una isla

Todo Chile es un campo de concentración

(Jaime Quezada, 1973)

\section{Un mundo y un lenguaje hechos trizas}

La violencia represiva de la dictadura militar chilena arrasó no sólo las identidades sociales que habían sostenido el proyecto político de la "vía chilena al socialismo", sino también los lenguajes con los que podía ser dicha y representada culturalmente la derrota histórica del proyecto de transformación global que ésta había encarnado. El sistema de campos de concentración y tortura que puso en marcha la dictadura de Pinochet tuvo, de hecho, un impacto radical sobre todos los órdenes de la vida social y, entre ellos, afectó decisivamente a la capacidad de los sujetos para describir, expresar y dar cuenta mediante el lenguaje de la violencia a la que se les estaba sometiendo.

No es de extrañar porque, como señala Gabriel Gatti (2011), las políticas represivas de las dictaduras del Cono Sur produjeron, además de sus inmediatos efectos políticos, una catástrofe del sentido y de la identidad que derivó, además, en lo que denomina una "catástrofe de las palabras" o de la representación que obliga a construir nuevos lenguajes para decir aquello que los lenguajes vigentes hasta el momento serían incapaces de representar. En un texto ya clásico, señalaba Elaine Scarry al respecto:

El dolor extremo destruye el yo de la persona y su mundo entero. [...] Pero el dolor extremo también destruye al lenguaje: si el contenido del mundo de una persona se desintegra, el contenido de su lenguaje se desintegra también; cuando el yo se derrumba aquello que podría expresarlo desaparece también (Scarry, 1985: 35).

Este artículo analiza uno de los modos en los que algunos detenidos, desaparecidos o supervivientes chilenos abordaron creativamente la paradoja de querer dar cuenta, a través del lenguaje poético, de una situación de violencia extrema para la cual carecían de lenguaje, porque la propia violencia represiva lo había hecho trizas. ¿Cómo, pues, dar cuenta de esa experiencia que derrumba, además del mundo del detenido, el lenguaje con el que podría expresarla? A esa contradicción trata- 
ron de responder, de un modo u otro, muchos supervivientes que dieron testimonio de lo ocurrido en el interior de los campos de concentración en soportes muy diferentes.

Algunas publicaciones del exilio como Literatura chilena en el exilio, Barco de papel o Araucaria de Chile editaron en fechas tan tempranas como 1974 poemas relacionados con la experiencia concentracionaria y con la represión. A lo largo de la década, algunas antologías poéticas incluirían en sus páginas poemas escritos en los campos por poetas anónimos o por supervivientes. Fue el caso de Chile: poesía de la resistencia y del exilio, compilada por Omar Lara y Juan Armando Epple en 1976, pero no publicada hasta 1978 en Barcelona; Los poetas chilenos luchan contra el fascismo, editado en el Berlín oriental por Sergio Macías (1977); Chile: poesía de las cárceles y del destierro, editado en Madrid por Aurora de Albornoz (1978) ${ }^{1}$; o Il sangue e la parola. Poesi del carcere e dai lager dall 'interno dal Cile e dall'esilio, publicado en Roma por Ignacio Delogu (1978). En todas ellas aparecían algunos poemas escritos en el interior de los campos de concentración chilenos, la mayoría de ellos por autores anónimos, con la notable excepción del poema "Estadio Chile" escrito por Víctor Jara en el propio estadio días antes de morir. En estas publicaciones tempranas la poesía concentracionaria se inscribía nítidamente en un paradigma antifascista, que hacía de los poetas anónimos combatientes de un nuevo cuño².

A los poemas publicados en esas revistas y antologías y en otras más recientes (Goldschmidt Wyman, 2002 o Silva-Cáceres, 2013) hay que añadir un libro insólito que supuso una apuesta única por reconstruir

\footnotetext{
${ }^{1}$ Aurora de Albornoz, poeta exiliada española y especialista de escrituras en el exilio escribía en el prólogo: "No os conozco, compañeros perseguidos, compañeros secuestrados, compañeros exiliados, compañeros torturados, compañeros asesinados... Mas permitidme que os llame así: 'Compañeros'. [...] Dejadme agradeceros, compañeros, estos poemas y fragmentos de poemas que tengo aquí, y que miro ahora: hablan de hombres que callaron los nombres de otros, y acaso tuvieron que pagar su silencio con su vida; hablan de huelgas de hambre y castigos inhumanos; hablan de mujeres torturadas; hablan de hijos arrebatados a sus padres; hablan, en fin, del Terror" (1978: 11).

${ }^{2}$ Sergio Macías en el prólogo a Poetas chilenos contra el fascismo escribía: "Los poetas sufren el martirio, la persecución, el exilio. Son combatientes activos de su clase, del pueblo. Tienen plena autoridad moral para expresar su arte revolucionario contra aquellos que asumieron la responsabilidad de traicionar a la patria y destruir su patrimonio cultural. Los trabajos que hemos recogido se ubican claramente en la lucha que realizan los poetas chilenos contra el fascismo" (1977: 5).
} 
el lenguaje poético en relación con la experiencia concentracionaria: Dawson, de Aristóteles España, publicado en Barcelona en 1985.

¿Cómo afrontaron este autor y los prisioneros anónimos de los campos chilenos la dificultad de representar poéticamente la experiencia concentracionaria y los efectos devastadores que ésta produce en la subjetividad? ¿De qué modo conjuraron la "catástrofe de la representación" que produjo esa violencia extrema y trataron de reconstruir un lenguaje capaz de dar cuenta, aunque fuera lateralmente, de esa experiencia límite?

\section{La escritura poética en el campo de concentración}

Es sabido que el sistema de campos de concentración chileno durante la dictadura de Pinochet fue variado y evolucionó notablemente con el tiempo. Por ello, centros destinados principalmente a la tortura y la violencia extrema, en los que ningún tipo de distensión era posible, convivieron con espacios concentracionarios estabilizados en los que a pesar de la situación de excepción y la violencia generalizada, los prisioneros tuvieron una cierta capacidad de auto-organización (Guerrero, 2000: 140). Ejemplos paradigmáticos de esta modalidad concentracionaria fueron los casos de Isla Dawson y Chacabuco, en los que los prisioneros llevaron a cabo acciones y proyectos, siempre difíciles y marcados por la precariedad, con el objetivo de reconstruir los lazos colectivos y las identidades políticas que el Golpe Militar de 1973 habían quebrado por completo. El poeta Jorge Montealegre narra la sorprendente función que la poesía cumplió en algunos de estos campos:

En febrero del 74, alejados del infierno que había sido el Estadio [Nacional] y de lo que, seguramente, era la cotidianidad de quienes estaban "libres" bajo el terror, en Chacabuco nos dimos ciertos "lujos" que nos permitieron sobrellevar la prisión y cuidar nuestra salud mental autoirónicos: tuvimos una organización -el Consejo de Ancianos- $y$, gracias a ella, concursos de poesía y canciones.

En el primer concurso, de febrero de 1974, se presentaron poco más de 40 poemas. De ellos se seleccionaron diez... todos ellos ganadores, porque la idea era compartir y no competir. Los diez poemas pertenecen a seis autores, ya que algunos seleccionaron más de uno: Santiago Caviares, Guillermo Cisternas, Eugenio García, Jorge Montealegre, Rafael Salas, y Osvaldo Yáñez. Premios a repartir: un Chacabuco tallado en 
madera, un tarrito de café, unas lonjas de fiambre para el pan. Además, un hermoso diploma hecho a mano, seguramente por algún arquitecto prisionero. Más el aplauso de los compañeros y su eco que sigue en la memoria (en Goldschmidt Wyman, 2002: 24).

Así, la escritura poética cumplía un doble cometido en el interior de los campos. Por una parte, se integraba en una serie de prácticas colectivas que buscaban rearticular los lazos que la violencia generalizada había roto entre los prisioneros. Los supervivientes refieren, de hecho, una gran variedad de acciones -las reuniones de discusión, organización de talleres y de concursos poéticos, de bibliotecas y seminariosque, aunque no resultaran amenazantes para el gobierno de los campos, sirvieron para reconstruir la sensación de pertenencia a una comunidad que la dictadura trataba de quebrar. De ese modo, aunque de un modo no explícitamente confrontativo, esas prácticas recusaban la lógica del aislamiento y el individualismo que los militares trataban de imponer, enmarcándose, por tanto, en la lógica que James C. Scott denominó la "infrapolítica de los grupos subordinados"3 cuya "invisibilidad es, en buena medida resultado de una acción deliberada, de una decisión táctica consciente del equilibrio de poder" (1990: 217).

Por otra parte, la escritura poética tuvo el cometido de elaborar la experiencia traumática vivida en los campos y de reconstruir la relación quebrada con el lenguaje derivada de esa "catástrofe de las palabras" a la que aludíamos anteriormente. La experiencia vivida en los campos, supuso, en muchos casos, procesos de cosificación, deshumanización y animalización de los prisioneros que, unidos a la violencia extrema, llevaron a procesos radicales de desubjetivación y a vivencias extraordinariamente traumáticas: ¿cómo representarlas en el discurso?, ¿cómo construir una posición para hablar de esas vivencias que, aparentemente, se hallaban más allá de cualquier lenguaje?

Los poemas escritos en el interior de los campos ensayaron diferentes formas de articular un lenguaje capaz de capturar, aunque fuera de forma elusiva, algo de esa experiencia tan difícilmente representable. Algunos de ellos suponían una recusación explícita del discurso oficial en torno a la violencia de Estado y se proponían como un contradiscurso en el que, de algún modo, podría cristalizar una verdad esencial, aunque

\footnotetext{
${ }^{3}$ En el artículo de Jorge Montealegre (2009) sobre las formas de la resistencia en los campos, estas ya aparecen pensadas desde este paradigma.
} 
esta fuera una ficción poética: "No puedo dejar de hablarte, padre/ los diarios mienten,/ todos mienten,/ desde el boletín oficial,/ el periodista,/ el impresor,/ la tinta,/ los avisos económicos,/ la canillita,/ a mi me fusilaron/ en la noche y a pleno campo/... no me arranqué" (Anónimo, en Goldschmidt Wyman, 2002: 155). El hablante lírico imaginaba una situación ficticia -su propia muerte pasada- para, desde el no lugar de la muerte, erigirse en contradiscurso acusatorio de una realidad borrada institucionalmente.

En esa misma tendencia ficcionalizadora, algunos poemas optaron por aludir a la realidad del campo a partir de la representación de otro lugar, definido por una relación de oposición a la vida del campo, bien de forma directa ("casas que estarán llenas de bullicio/ juguetes y travesuras; de coquetería, artesa/ y amorosos labios" (Montealegre, en Goldschmidt Wyman, 2002: 113) o por la figuración de un destinatario que estuviera fuera de ese espacio, al cual se le relatara lo que allí ocurría, como en el caso del poema anterior. En el Poema uno, de Rafael E. Salas-Glaziou, escrito en el Estadio Nacional en septiembre de 1973, se leía: “[...] Pero piensa, hermano, / que más allá del estribillo metálico, / inútil y siniestro, / más allá del terror planificado, / del insulto y el vejamen, / de la vergüenza y del hambre, / más allá de la tortura y del escarnio / está la risa de tu mujer y tus chiquillos / o el susurro amoroso de tu novia / y esa luz húmeda en los ojos de tu madre, / pero más que todo eso / [...] está la simple, conocida y heroica / fortaleza del pueblo" (en Goldschmidt Wyman, 2002: 130). Daba la impresión, pues, de que hacía falta imaginar un punto de vista exterior al campo para poder, desde allí, hacer en cierta medida inteligible lo ocurrido en su interior.

Es el caso del poema "No hay olvido" de Rolando Rojo, escrito el 7 de febrero en Chacabuco (Goldschidt Wyman, 2002: 125-126), y que en las antologías de los setenta aparecía como anónimo. En él, el espacio y la experiencia concentracionaria solo es decible desde un tiempo futuro y desde un espacio exterior, cuando lo vivido en los campos se convirtiera en olvido: "Cuando se haga familiar el paisaje / y reconozca la calle el eco de mis pasos, / cuando de puertas y ventanas se asome el vecindario / y el ladrido de un perro anuncie mi llegada. / ¡Olvidaré todo!". Ese tiempo y espacio futuro aparecía representado bajo el signo de la cotidianidad y de lo hogareño, es decir, como una existencia en la que la experiencia pudiera ser leída como propia frente a la impropiedad de la existencia concentracionaria. Sin embargo, en ese utópico 
espacio postconcentracionario emerge la posibilidad de recuperar la experiencia del campo a través de la memoria: "el pueblo abandonado / que revivió con las voces de unos hombres/ que no se conocían”. Así, pues, lo vivido en el interior del campo solo puede ser representado desde ese afuera imaginario que, en la lógica del poema, es la condición de posibilidad para que el hablante pueda reconocerse como sujeto de la experiencia concentracionaria.

Frente a esa poética de la exterioridad, otros prisioneros trataron de representar la experiencia inmediata del modo más directo posible. Pero se enfrentaban, como es lógico, a la dificultad de estructurar un discurso coherente y organizado en torno a una experiencia que, por su carácter traumático, aparecía como fragmentada y carente de sentido. En "Palabras", de Horacio Silva, se ensayaba una poética de la yuxtaposición, en la que cada verso aludía a una de las violencias a las que eran sometidos los prisioneros: "arrancamiento de dientes / golpes con puños / golpes con los pies / golpes con las rodillas / golpes con mangueras / golpes con tubos / golpes con laque / golpes con culata / arrancamiento de cabellos / golpes simultáneos en los oídos / ingestión de aguas con mangueras / ingestión de excrementos / ayuno forzado" (en Bianchi, 1990: 18-19) ${ }^{4}$. Esa estructura poética da cuenta de un hablante traumado por la violencia e incapaz de establecer relaciones, jerarquizar y organizar sintácticamente todos esos elementos que se presenta poéticamente más como una sucesión de golpes que como un todo organizado.

Entre los poemas que optaron por esta representación más directa, es detectable un énfasis poético en algunos elementos emblemáticos del universo concentracionario, que por su irradiación simbólica tienen la capacidad de aludir de forma metonímica a todo el campo de concentración: la alambrada ("pero la tengo aún, / la alambrada... /pero no por mucho tiempo" (anónimo escrito en Ritoque, Macías, 1977: 306); las esposas ("Sentía frío, / tanto frío, /y las esposas me apretaban" (anó-

\footnotetext{
${ }^{4}$ Soledad Bianchi señalaba: “ 'Palabras', de Horacio Silva, verdadero ‘diccionario o vocabulario anormal de la tortura' [...] Larga letanía de distintos procedimientos utilizados como forma de tortura por la dictadura chilena. Impresiones mínimas y casi monótonas (jamás se usa un verbo) que parecen extraídas de un documento. Aunque nunca se da una opinión personal, la objetividad no provoca la indiferencia del lector sino que, por el contrario, las descripciones -en una desnudez casi abstracta- duelen más y mueven a la rebeldía para que acabe esta interminable y repetida brutalidad, este ritmo sangriento y doloroso que va creciendo en una reiterada marea de macabra invención" (Soledad Bianchi, 1990: 18).
} 
nimo, Goldsmicht Wyman, 2002: 159). Entre esos elementos emblemáticos, el pabellón de prisioneros aparece en algunos poemas como un micromundo intensamente dislocado que condensa la lógica de la excepción y la violencia extrema:

En este pabellón de prisioneros

no se duerme esta noche,

porque el fascismo ha cerrado su hocico

con trozos de nuestra carne

en sus colmillos (Anónimo, en Macías, 1977: 25).

\section{Un lenguaje para la tortura}

En el corpus de poemas escritos en los campos chilenos, la representación directa de la tortura y las formas de violencia extrema no es muy recurrente. Pareciera como si la cercanía del acontecimiento traumático dificultara enormemente su representación discursiva. Sin embargo, algunos poemas escritos con posterioridad sí aluden directamente y con contundencia a la escena de tortura. Eduardo Llanos, en su texto "Interrogatorio" aludía a ella desde un paradigma casi sacrificial: "Sobre el somier electrificado / al presionar dio el penúltimo alarido / y su cuerpo desnudo se contrajo / como potranca desollada en un salar" (en Goldschmidt Wyman, 2002: 185).

En los poemas escritos en el interior, sin embargo, parecía necesario un gesto de distanciamiento, que permitiera aludir a la práctica y las técnicas de la tortura desde un lugar y desde una estética desplazada. El poema titulado "ELECTRA" utilizaba una retórica propia de la poesía amorosa para aludir a la tortura con electricidad, estableciendo un violento choque semántico entre la tonalidad amorosa y la representación de la violencia extrema sobre el cuerpo: "Me desnudé nervioso. / Con la misma zozobra de mis 18 años. / Y me tendí en tu cama extraña. /Cosa curiosa: ataron tu lecho a mis espaldas. / Para que no me moviera. / Inesperada, recorriste mi cuerpo, / induciéndome espasmos crueles, / No, no haré más el amor contigo. / Mujer vulgar y corriente". (Anónimo, en Macías, 1977: 29).

En otros casos, la tortura se integraba en un proceso más amplio, en el que el hablante lírico mostraba su desorientación e incomprensión ante una violencia para la que no encontraba razón ni causa, y cuyo sentido se le escapaba por completo. En el siguiente poema, de hecho, 
el sujeto se dirigía a su padre y, tras relatar una serie de recuerdos inconexos y sin apenas relación, le relataba una escena de violencia extrema que no era capaz de integrar en su experiencia de mundo (" $¿$ alguna vez me pegaste tanto?"). En la desconexión de los recuerdos, en los encabalgamientos abruptos y en la dislocación interna de los versos podían leerse los signos de una subjetividad desestructurada por la violencia pero luchando por construir una posición, bien que inestable y vacilante, para hablar de ella.

Recordaba haber comprado un libro de historia, también que una mujer me había sonreído, padre, me pegan, me amarran. El cordel se me confunde con la carne, con los vellos.

Siento que la cabeza no me pertenece, ¿alguna vez me pegaste tanto?

¿O mi madre?

En la herida han puesto la corriente, y sólo he recordado el corredor, cualquier corredor, y más tarde estoy de nuevo trabajando, resistiendo lo que no se resiste, cerrando los ojos cuando es imposible cerrarlos, y teniendo la certeza de que no sé nada de lo que ocurrirá un minuto más tarde.

(Anónimo, Goldschmidt Wyman, 2002: 153).

La práctica de la tortura también fue abordada por algunos de estos poetas anónimos a partir de los efectos que generaban en aquellos que la sufrían, representando sujetos derrumbados por ella y quebrados por entero por la electricidad y las golpizas. Uno de estos poemas, entre los más incisivos de toda la serie de producciones anónimas, optó por reformular la experiencia del campo a partir de imágenes fantasmagóricas, que relacionaban los efectos de la violencia con la locura y que leían el derrumbe subjetivo de los prisioneros a partir de imágenes poderosas y lacerantes: "Me contaron que alguien los vio / y que están locos. / Los han vestido de niños /y amarrado con cordeles / mano con mano / pie con pie / como una cuncuna. / Me contaron que llaman a sus madres / y que gimen / en los mamelucos azules / repitiendo palabras sin sentido / de regreso a los rincones / más tibios y seguros" (Anónimo, 
en Albornoz, 1978: 31). Esas imágenes desoladoras derivaban en una conceptualización poética del difuso estatuto del desaparecido: "Nadie sabe sus nombres / ni que existen / pero alguien los vio / en la sala de cuartel donde / los torturaban / repitiendo / pálidos / azules / sumisos / lo que eran antes del horror" (Anónimo, en Albornoz, 1978: 31). El hablante lírico, como puede verse, diseñaba una relación doblemente mediatizada con el universo del desaparecido/torturado: le "contaron que alguien los vio". Aun en esa localización dislocante ${ }^{5}$ que es el campo de concentración, el poema ubicaba pues a los torturados en un grado mayor de excepcionalidad y dislocación, en una lógica de sentido que escapaba a la comprensión del hablante, que únicamente hallaba imágenes alucinatorias para expresar poéticamente lo que queda del sujeto tras el horror.

\section{Poesía en Dawson: una enunciación paradójica}

Cuando fue internado en Isla Dawson, Aristóteles España contaba apenas con diecisiete años. En el campo de concentración austral cumpliría dieciocho y escribiría el poemario más importante de la literatura concentracionaria chilena. Publicado en una primera versión con el título de Equilibrios e incomunicaciones (1980) y posteriormente con el más directo de Dawson (1985) el poemario presentaba una cierta estructura narrativa: se abría con el poema "Llegada", que efectivamente narraba cómo los prisioneros "llegamos de la barcaza con las manos en alto / a una playa triste y desconocida", y se cerraba con el poema "Partida", en el que narra su salida del campo de concentración. Entre medio, veintidós "Poemas escritos en el Campo de Concentración de 1sla Dawson, Septiembre 1973 - Septiembre 1974”, tal como reza su subtítulo.

En el poema "Más allá de la tortura", el sujeto poético hablaba desde un espacio marcado por la alteridad ("fuera del espacio y la materia"), una alteridad radical que hacía entrar en crisis todas las categorías con las que organizamos culturalmente nuestra experiencia.

Fuera del espacio y la materia,

En una región altiva (sin matices ni colores)

Llena de un humo horizontal

Que atraviesa pantanos invisibles,

\footnotetext{
${ }^{5}$ Así lo define Giorgio Agamben en sus estudios sobre los campos (2000).
} 
Permanezco sentado

Como un condenado a la cámara de gas.

Descubro que el temor es un niño desesperado,

Que la vida es una gran habitación

O un muelle vacío en medio del océano.

Hay disparos, ruidos de máquinas de escribir,

Me aplican corriente eléctrica en el cuerpo.

Soy un extraño pasajero en viaje a lo desconocido,

Arden mis uñas y los poros, los tranvías,

En la sala contigua golpean a una mujer embarazada,

Las flores del amor y la justicia crecerán más adelante

Sobre las cenizas de todas las dictaduras de la tierra (España, 1985: 39).

Si bien los primeros versos podían hacer pensar en la descripción de un espacio espiritual, España reconducía políticamente esa zona de alteridad a través de un símbolo muy reconocible en el imaginario cultural contemporáneo: el prisionero condenado a la cámara de gas. En los versos siguientes, constata la presencia de elementos que apuntan a escenas de violencia y burocracia, pero que no se definen en relación con el sujeto, sino en su pura existencia desnuda: "Hay disparos, ruidos de máquinas de escribir", como si el sujeto hubiera abdicado de la posibilidad de hacer una experiencia de ellos. Incluso cuando esos elementos violentan su cuerpo, el hablante se limita a levantar acta, descargando aparentemente de todo carácter experiencial al verso: "me aplican corriente eléctrica en el cuerpo". Es más, cuando trata de describir el efecto de la corriente eléctrica sobre su cuerpo, sólo puede hacerlo a través de fragmentos sumamente heterogéneos en los que se pone en situación de equivalencia partes del cuerpo violentado con elementos totalmente ajenos a él (los tranvías). Ello remarca la incapacitación del sujeto lírico, traumado por la violencia, para jerarquizar y establecer relaciones de sentido entre los diferentes elementos del entorno: "Arden mis uñas y los poros, los tranvías/ En la sala contigua golpean a una mujer embarazada".

Esa dificultad, que se acerca por momentos a la paradoja testimonial - dar fe subjetiva del derrumbe de esa misma subjetividad-se desarrolla en un poema significativamente titulado "Apuntes". En él, se presentan fragmentos de experiencia que, a pesar de la sucesión temporal, carecen de continuidad narrativa. 
Me fotografían en un galpón

como a un objeto

una, dos, tres veces,

de perfil, de frente,

confeccionan mi ficha con esmero:

"soltero, estudiante, 17 años,

peligroso para la seguridad del Estado" [...]

Se estrellan sus puños

en mis oídos.

Caigo.

Grito de dolor.

Voy a chocar contra una montaña.

Pero no es una montaña.

Sino barro y puntapiés,

$\mathrm{y}$ un ruido intermitente

que se mete en mi cerebro

hasta la inconciencia (29-31)

El hablante representa el proceso por el cual es convertido en un objeto disponible para la tecnología represiva: explicita, pues, la idea de cosificación que la gran mayoría de los supervivientes señala en su experiencia de los campos. No por casualidad, la violencia física que viene después es representada fuera de cualquier interacción subjetiva, dado que el sujeto que habla se ha derrumbado: los puños "se estrellan", desconectados de cualquier voluntad contra sus oídos; la caída y el grito aparecen como acciones desconectadas -su distancia es reforzada por los signos de puntuación y la separación del verso- y lo que queda del sujeto se ve incapacitado para distinguir entre los puntapiés de los militares y las fuerzas de la naturaleza: "Voy a chocar contra una montaña./ Pero no es una montaña./ Sino barro y puntapiés".

En buena parte de sus poemas España enfatiza la cualidad de excepción de la existencia en el universo concentracionario, inscribiendo al sujeto lírico en un orden diverso al de la experiencia cotidiana:

Hay esferas que explotan como ecos destrozados, y se pierde la noción de todo,

-es difícil de explicar-

la celda es fría (43) 
Qué hacer en esta hora, caminar dentro de la celda, dar vueltas, regresar al vientre de la idea, irse definitivamente, al rincón más oscuro de la angustia (49)

Esos dos fragmentos apuntan, precisamente, a la dificultad de inscribir lo subjetivo en el universo concentracionario: la temporalidad de la celda se halla sustraída al tiempo de la experiencia, y no es posible organizar en su interior una relación de propiedad con los objetos ni con los acontecimientos que salen a su paso. De hecho, es importante resaltar la ausencia de trabazón subjetiva entre los diferentes elementos poéticos: los verbos están en infinitivo o son impersonales y ninguna subjetividad se ofrece como instancia que suture las diversas posibilidades ofrecidas por el poema para la existencia en el interior de la celda.

No deja de resultar paradójico que todos esos elementos apunten claramente a regiones de la subjetividad ("se pierde la noción de todo" "el vientre de la idea" "el rincón más oscuro de la angustia"), pero carezcan por completo de marcas de un sujeto responsable de ese enunciado. Esa contradicción probablemente cifre la dificultad de construir una posición capaz de dar cuenta discursivamente de los procesos de desubjetivación que tienen lugar en la dinámica concentracionaria: ¿qué sujeto puede dar cuenta de su propio derrumbe?

Giorgio Agamben (2000) definió la posición del testigo de los campos como la de aquel que testimonia de una doble imposibilidad de testimoniar: por una parte, de la del hundido, que es el que ha vivido la experiencia de los campos hasta el fin y por ello mismo no puede dar cuenta de ella; $y$, por otra parte, de su propia imposibilidad, en tanto que no ha podido ocupar plenamente una posición de sujeto ante el acontecimiento que describe. Es por ello que el testigo de los campos testimonia de un proceso de desubjetivación radical y, por ello, la estructura del testimonio puede ser leída en los términos de una subjetivación en una absoluta desubjetivación. Esa enunciación paradójica, que en otro lugar he definido como una "imposible voz" (Peris Blanes, 2005), atraviesa los poemas de España de parte a parte.

En el poema "Llanuras y silencios" (1985: 55-57) España tematiza el acto material de la escritura poética en el interior del campo, pero lo hace bajo el signo de la negación ("No escribiré poesía esta semana"). 
Esa declaración se enmarca en una breve serie de frases fragmentarias y sin aparente ligazón entre ellas, cada una con una tonalidad emotiva diversa. Esa enunciación oscilante puede leerse como efecto de una subjetividad dislocada, incapaz de ordenar su experiencia de la realidad en un discurso unitario, y como un síntoma, pues, de esa condición paradójica de la poética testimonial atravesada por procesos contradictorios de subjetivación y desubjetivación.

No escribiré poesía esta semana.

Hoy entramos al otoño, cada día estoy más enfermo.

¿Cómo estás? ¿En qué centro de reclusión? ¿En qué Sala?

¿O en qué fosa?

Se repite tu nombre en mis pupilas, veo cuervos en los postes y en las ramas.

¿Ha llegado el fiscal para juzgarnos?

Estoy bastante mal,

Confundo cosas, necesito

ver

el

cielo

esta

mañana,

Escuchar el susurro de las olas cuando lloran

O los últimos espasmos de una aurora ennegrecida.

¿Recuerdas diciembre en "Agua Fresca"?

quisiera escribir un relato,

lentamente recupero la entereza,

me gustan las frutas y tu pelo,

hace frío,

tengo breves contactos con la tristeza,

me atrapa a veces,

después huyo hasta otros archipiélagos;

son las $10 \mathrm{~A}$. M.

el futuro -que ya sabemos que se empieza a construirserá doloroso y noble como un parto (1985: 57).

Como se ha mostrado anteriormente, muchos de los poetas anónimos de los campos chilenos imaginaron un espacio de alteridad desde el que poder imaginar y representar la experiencia concentracionaria. 
En este poema, sin embargo, ese lugar otro, el del apóstrofe lírico, es un lugar tan atravesado por la violencia extrema como el del sujeto poético (“¿Cómo estás? ¿En qué centro de reclusión? ¿En qué Sala? ¿O en qué fosa?"): todo el espacio de lo posible se ha convertido, pues, en un campo de concentración.

\section{Víctor Jara: poema interrumpido en el Estadio Chile}

E1 15 de septiembre de 1973, pocas horas antes de ser asesinado en el Estadio Chile, Víctor Jara escribió en dos hojas sueltas un poema sobre la experiencia vivida en el Estadio, convertido en campo de concentración improvisado. Interrumpido por los guardias, Jara entregó a Boris Navia el poema sin terminar, quien consiguió extraer del campo una copia tras ser violentamente torturado (Amorós, 2004).

El poema se abre con la constatación del carácter colectivo de la experiencia: el país entero pareciera haberse convertido en un campo de concentración. Y consigna, además, la muerte de seis compañeros, que preludian su asesinato inminente.

Somos cinco mil aquí

en esta pequeña parte de la ciudad.

Somos cinco mil.

¿Cuántos seremos

en total

en las ciudades y en todo el país?

Sólo aquí, diez mil manos que siembran

$\mathrm{y}$ hacen andar las fábricas.

Cuánta humanidad con hambre,

frío, pánico, dolor, presión moral, terror y locura!

Seis de los nuestros se perdieron

en el espacio de las estrellas.

Uno muerto, uno golpeado como

jamás nunca creí se podría golpear a un ser humano.

Los otros cuatro quisieron quitarse

todos los temores;

uno saltando al vacío,

otro, golpeándose la cabeza contra el muro,

pero todos con la mirada fija en la muerte. 
Tras esos versos explícitamente testimoniales y de una referencialidad desgarradora, en el tramo final el poema se volvía sobre sí mismo y reflexionaba sobre la posibilidad de erigir un canto en ese ambiente de violencia extrema. En esos últimos versos se reconocía claramente el estilo de las canciones de Jara, con sus rimas internas, acentuaciones abruptas y estructuras basadas en la contradicción. En ellos, el sujeto lírico convertía en materia poética su propia dificultad para hablar de un horror que desbordaba su capacidad de intelección y encontraba su meta en aquellos modos de expresión en que el lenguaje, llegado a un punto límite, deja de ser tal: el silencio y el grito.

Canto que mal me sales cuando tengo que cantar espanto.

Espanto canto el que vino como que muero de espanto.

Se verme entre tanto y tantos momentos del infinito en que el silencio y el grito son las metas de este canto. Lo que veo; nunca vi lo que he sentido y lo que siento hará brotar el momento...

Entre el silencio y el grito, el poema busca pues un espacio instersticial que es, en buena medida, el que ocupa la poesía concentracionaria chilena, del que el texto inacabado de Jara es, quizás, su ejemplo más emblemático. Es, de hecho, la interrupción brutal de la escritura, que sabemos antesala de la muerte violentísima de su autor, lo que lleva al extremo una de las características de la poesía concentracionaria: que el valor de su testimonio radica más en sus agujeros y, en definitiva, en lo que no alcanza a decir porque su entorno brutal se lo impide, que en aquello que logra, aunque precariamente, representar.

\section{Bibliografía}

Agamben, Giorgio. 2000. Lo que queda de Auschwitz. El archivo y el testigo. Homo Sacer III. València: Pre-Textos.

Albornoz, Aurora de (ed.) 1978. Chile: poesía de las cárceles y del destierro. Madrid: Ediciones Conosur. 
Amorós, Mario. 2004. (12/09). El último aliento de Víctor Jara. La fogata. http://www.lafogata.org/chile/allende2.htm [Acceso 01/04/2016].

Bianchi, Soledad. 1990. Sobre poesía anónima de prisiones. En Poesía chilena. (Miradas, enfoques, apuntes). Santiago de Chile: Documentas, 11-19.

Delogu, Ignacio. 1978. Il sangue e la parola. Poesi del carcere e dai lager dall'interno dal Cile e dall'esilio. Roma: Casa Editrice Roberto Napoleone.

España, Aristóteles. 1985. Dawson. Bruguera: Santiago de Chile.

Gatti, Gabriel. 2011. Identidades desaparecidas. Peleas por el sentido en los mundos de la desaparición forzada. Argentina: Prometeo Libros.

Goldsmicht Wyman, Eva (ed.). 2002. Los poetas y el general. Santiago de Chile: LOM.

Guerrero, Manuel. 2000. Democratización chilena y control social. La transición del encierro. En Salazar, Mauro \& Valderrama, Miguel. Dialectos en transición. Politica y subjetividad en el Chile actual. Santiago de Chile: LOM, 129-161.

Macías, Sergio (ed.). 1977. Los poetas chilenos luchan contra el fascismo. Berlin RDA: Comité Chile Antifascista.

Montealegre, Jorge. 2009. Humor gráfico y evasiones imaginarias en la resistencia cultural de prisioneras y prisioneros políticos de Chile y Uruguay: acciones colectivas y condiciones para la resiliencia en la prisión política. Diálogos de comunicación 78: 1-15.

Peris Blanes, Jaume. 2005. La imposible voz. Memoria y representación de los campos de concentración en Chile: la posición del testigo. Santiago de Chile: Cuarto Propio.

Quezada, Jaime. 2013. El año de la ira. Diario de un poeta chileno en Chile. Septiembre 1973-Septiembre 1974. Santiago de Chile: Catalonia.

Scarry, Elaine. 1985. The body in pain. The making and unmaking of the world. New York/Oxford: Oxford University Press.

Scott, James C. 1990. Los dominados y el arte de la resistencia. México: Era.

Silva-Cáceres, Raúl (ed.). 2013. La libertad no es un sueño. Antología de la poesía chilena de la resistencia. (Del exilio, las cárceles, los campos de concentración.). Prólogo de Julio Cortázar. Santiago de Chile: Signos. 